\title{
Consumo de bebidas alcohólicas en la adolescencia temprana y su atención médica
}

Alcohol consumption in early adolescence and medical care

Las bebidas alcohólicas, producto de la fermentación de cereales o jugos de frutas, han sido utilizadas durante miles de años por distintas civilizaciones, como la egipcia, la china, la grecorromana, las culturas precolombinas, entre tantas otras, ya sea en rituales o para uso recreativo social. En la civilización griega, se realizaban los cultos dionisíacos, en los que los participantes, a través de la embriaguez, buscaban el acercamiento a su dios. Para la mitología romana, Dioniso asumió el nombre de Baco y su nombre persiste en los actos bacanales, en referencia al desenfreno o desinhibición que caracterizan a la intoxicación etílica aguda (Figura 1).

En la Edad Media, las bebidas alcohólicas eran conocidas como "espíritus" y se utilizaban ampliamente con fines curativos. ${ }^{1}$

Durante el siglo XVIII, el consumo de bebidas alcohólicas aumentó en la población, favorecido por la legislación que fomentaba el uso de cereales para elaborar bebidas destiladas, sumado al mayor desarrollo industrial de las civilizaciones.
En el siglo XIX, se percibió un cambio de actitud y surgieron campañas para promover el uso moderado de alcohol. Fue así como, en algunos países, hasta se prohibió la fabricación, venta, importación y exportación de alcohol. La ley seca trajo aparejado el comercio ilegal y el contrabando de bebidas alcohólicas para satisfacer la demanda del mercado, hecho que obligó a cancelar la prohibición. En nuestro país, se aplica una ley seca especial en época de elecciones horas antes y después de los comicios.

Hoy en día, en nuestra sociedad, el alcohol es la droga psicoactiva más común entre los adolescentes. ${ }^{2}$ Distintos trabajos coinciden en que el $49 \%-76 \%$ de los jóvenes de entre 10 y 14 años ha consumido bebidas alcohólicas; ${ }^{3-5}$ este es el rango de edades más vulnerable para el inicio del consumo de alcohol. Esta situación se repite en nuestro país y en otros de América Latina.

La Organización Mundial de la Salud (OMS) recomienda la abstinencia de alcohol en menores de 18 años, ya que el riesgo de dependencia

Figura 1: El triunfo de Baco, de Velázquez, pintura de 1629, conservada en el Museo del Prado, Madrid. Representa al dios Baco, quien ofrece vino a los hombres para que se olviden temporalmente de sus problemas y alude al efecto embriagador del alcohol.

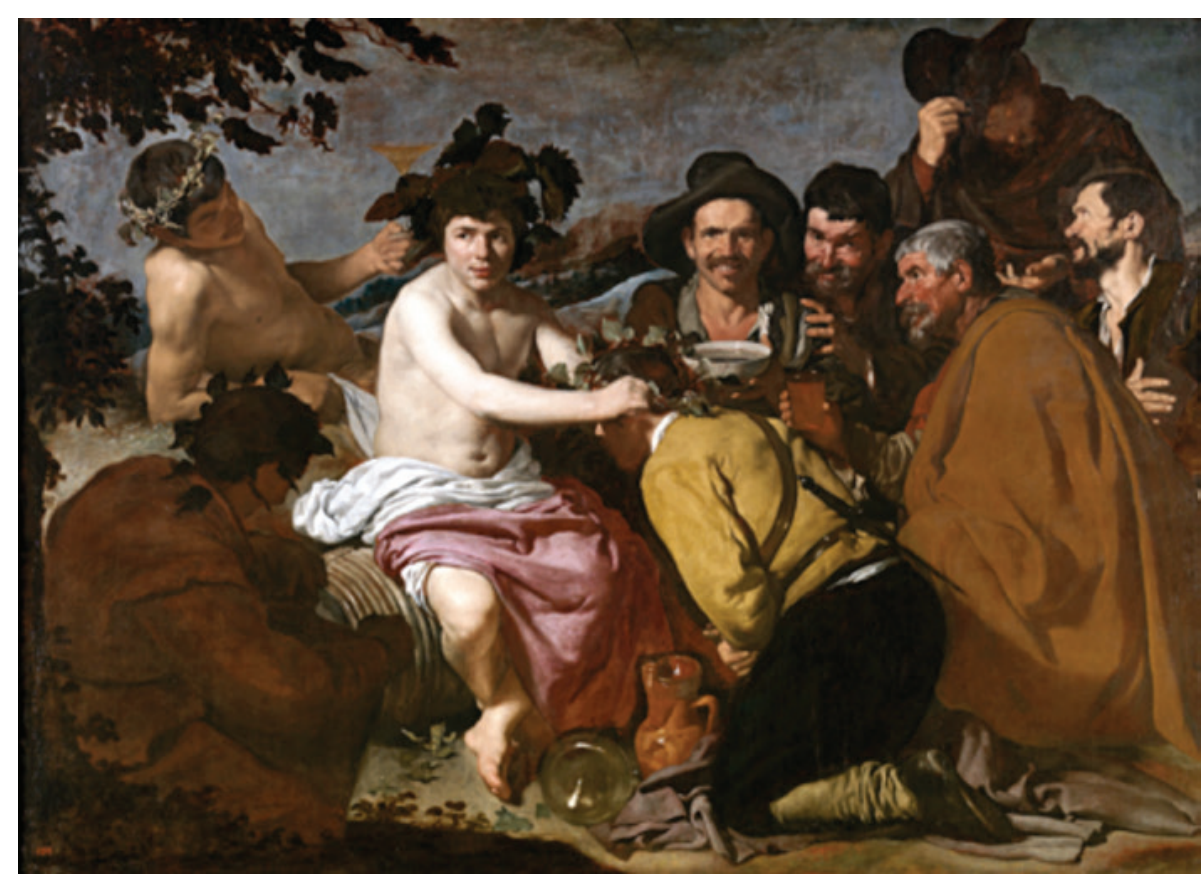


futura disminuye cuanto más tarde es el inicio del consumo de bebidas alcohólicas. Coincidiendo con la legislación actual que, en nuestro país, prohíbe la venta a menores de 18 años, queda en evidencia, de esta manera, que nos encontramos frente a un complejo problema de salud pública. Además, la modalidad actual de consumo que se observa en los jóvenes es el patrón del consumo abusivo o riesgoso de alcohol durante los fines de semana, en ámbitos de nocturnidad, al salir con sus pares, situación en la que existe mayor tolerancia familiar y del entorno., ${ }^{5,6}$

Este consumo episódico excesivo de alcohol -CEEA- (se refiere al consumo de grandes cantidades de alcohol en pocas horas), ${ }^{4}$ característico de las salidas de fines de semana de adolescentes y jóvenes apunta a la intoxicación etílica aguda, en la que se registran preferencias de bebidas destiladas de alta graduación alcohólica, como vodka, ginebra o tequila, ${ }^{5}$ a veces, también mezcladas con medicamentos, asociación que se conoce como jarra loca. ${ }^{7}$

Esta modalidad de consumo trae como consecuencias del estado de intoxicación alcohólica aguda mayor incidencia de accidentes de tránsito, situaciones de violencia familiar o callejera, embarazos no deseados y contagio de enfermedades de transmisión sexual. A esto hay que sumarle la acción de medicamentos u otras drogas ilícitas, ya que es frecuente ver policonsumo de sustancias.

Es en estos CEEA, durante los cuales los adolescentes consumen bebidas de alta graduación, cuando alcanzan niveles muy altos de alcohol en sangre en forma rápida, que se reflejan en un veloz deterioro del estado de conciencia. El coma alcohólico es un motivo de ingreso frecuente a los servicios de emergencia en jóvenes sin desarrollo de tolerancia alcohólica, es decir, en bebedores episódicos u ocasionales. Esta situación ejemplifica el consumo desenfrenado, sin límites que se puede apreciar en nuestra sociedad cotidianamente.

La prevención del consumo de alcohol y drogas debe abordarse y entenderse dentro del concepto global de educación para la salud. ${ }^{8}$ Es indispensable crear programas de concientización de los riesgos que genera el consumo episódico y abusivo de alcohol.

Borrás Santiesteban señala la falta de documentación que permite determinar el consumo de bebidas alcohólicas en adolescentes y de coordinación entre el área de salud y las escuelas, y manifiesta la necesidad de establecer una consulta para adolescentes. Otro aspecto para destacar del trabajo del mismo autor es que la vía más frecuente para obtener información sobre la prevención del consumo de bebidas alcohólicas fue la televisión y, en ningún caso, se mencionó al personal de salud.

Esto demuestra que los medios masivos de comunicación son muy importantes en la difusión de información sobre temas sensibles de salud, incluso las adicciones, y debería articularse con profesionales especialistas en el tema.

Dra. Silvia Cabrerizo

Pediatra, toxicóloga

Centro Nacional de Intoxicaciones Hospital Nacional Prof. Alejandro Posadas

http:/ /dx.doi.org/10.5546/aap.2016.396

\section{REFERENCIAS}

1. Contreras Morales CA, del Campo MC. Productos de la fermentación alcohólica; un beneficio para la salud [Internet]. [Acceso: 10 de junio de 2016]. Disponible en: http://bibliotecadigital.usbcali.edu.co/jspui/ bitstream/10819/2613/1/Fermentaci\%C3\%B3n\%20 alcoh $\%$ C3\%B3lica $\% 20$ un $\% 20$ proceso_Carlos $\% 20$ Contreras_USBCTG_2015.pdf.

2. Secretaría de Programación para la Prevención de la Drogadicción y la Lucha contra el Narcotráfico. Sexto Estudio Nacional sobre Consumo de Sustancias Psicoactivas en estudiantes de enseñanza media. Buenos Aires: SEDRONAR; 2014. [Acceso: 13 de junio de 2016]. Disponible en: http://scripts.minplan.gob.ar/octopus/ archivos.php? file $=4121$.

3. Schaffer C, Arizaga V, Albarenque M, Haseitel B. Alcoholismo en la adolescencia. Revista de Posgrado de la VIa Cátedra de Medicina 2004;139:24-8. [Acceso: 10 de junio de2016]. Disponibleen: http:/ / med.unne.edu.ar/revista / revista139/alcohol.htm.

4. Argentina. Ministerio de Salud de la Nación. Lineamientos para la atención del consumo episódico excesivo de alcohol en adolescentes. Buenos Aires: Ministerio de Salud de la Nación; 2012. [Acceso: 10 de junio de 2016]. Disponible en: http:/ / www.msal.gob.ar/saludmental/images/stories / info-equipos/pdf/2012-10-31_lineamientos-atencionalcohol.pdf.

5. Cabrerizo S, Varela S, Lutz MI. Encuesta sobre abuso de alcohol y medicamentos en adolescentes de cuatro escuelas del conurbano bonaerense. Arch Argent Pediatr 2014;112(6):504-10.

6. Míguez HA. Patrones culturales de la alcoholización social en estudiantes bonaerenses. Vertex Rev Argent Psiquistr 2009;20(87):325-8.

7. Cabrerizo S, Docampo P C. Alcohol y mezcla de fármacos: modalidad de abuso frecuente. Arch Argent Pediatr 2010;108(5):e111-3.

8. Pons Diez J, Berjano Peirats E. El consumo abusivo de alcohol en la adolescencia: un modelo explicativo desde la psicología social [Internet]. [Acceso: 10 de junio de 2016]. Disponibleen:http:/ / www.msssi.gob.es/alcoholJovenes / docs/consumoAbusivo.pdf. 